\title{
The effect Blended training on comparison with in-person training on self-care behaviors in type 2 diabetes patients
}

Mehrnoosh Khoshnoodifar

Assistant Professor of E-learning Planning, Department of E-learning Planning in Medical Sciences, School of Management, \& Medical Education, Shahid Beheshti University of Medical Sciences, Tehran, Iran

Zohreh Arabnezhad

* Msc, Department of E-learning Planning in Medical Sciences, School of Management, \& Medical Education, Shahid Beheshti University of Medical Sciences, Tehran, Iran. (Corresponding Author): Email:

ArabnejadZ1@mums.ac.ir

Hadi Tehrani

Associate professor, Social Determinants of Health research center, Mashhad University of Medical Sciences,

Department of Health Education and Health Promotion, Faculty of Health, Mashhad University of Medical Sciences, Mashhad, Iran

Somayeh Akbari farmad

Department of Medical Education, School of Medical Education, Shahid Beheshti University of Medical Sciences, Tehran, Iran.

Received: 18 March 2019

Accepted: 7 August 2019

DOI: 10.29252/ijhehp.7.4.333

\begin{abstract}
Background and Objective: Diabetes is one of the most common diseases caused by metabolic disorders. This disease is not definitive, but it can be controlled. Successful diabetes control depends largely on patient self-care because more than 95 percent of diabetes care is done by the patient himself. The purpose of this study was to determine the effect Blended training on comparison with inperson training on self-care behaviors in type 2 diabetes patients.

Materials and Methods: This study was a quasi-experimental study with two groups of blended training and in-person training in which 60 patients with type 2 diabetes were randomly divided into blended training and in-person groups. Data were collected by standard questionnaires of SDSCA (Diabetes Self-Care Behavior Inventory). For the blended training group, blended training programs were implemented and the in-person training group received the training in person at the health center. The results were analyzed by SPSS 16 software.

Results: Before the intervention, the mean and standard deviation of self-care score in the in-person training group was $3.3 \pm 0.74$ and three months after the intervention was $3.87 \pm 0.99$, In the blended training group before the intervention, the mean and standard deviation of self-care was $3.56 \pm 0.64$ and three months after the intervention was $4.6 \pm 0.85$, this difference was statistically significant in both groups. But this increase was in favor of blended training.

Conclusion: The results of this study showed that the use of blended training method is more effective in increasing the self-care of patients with type 2 diabetes than the in-person training. Therefore, the use of this method in controlling and reducing the complications of the disease is recommended in patients with type 2 diabetes.
\end{abstract}

Keywords: Self-care, blended training, type 2 diabetes

Paper Type: Research Article.

Citation (Vancouver): Khoshnoodifar M, Arabnezhad Z, Tehrani H, Akbari farmad $\mathrm{S}$. The effect Blended training on comparison with in-person training on self-care behaviors in type 2 diabetes patients. Iran J Health Educ Health Promot. Winter 2020;7(4): 333-342. [Persian]

- Citation (APA): Khoshnoodifar M., Arabnezhad Z., Tehrani H., Akbari farmad S. (Winter 2020). The effect Blended training on comparison with in-person training on self-care behaviors in type 2 diabetes patients. Iranian Journal of Health Education \& Health Promotion., 7(4),333-342. [Persian] 


\section{بررسى تاثيرآموزش تركيبى در مقايسه با آموزش حضورى بر رفتارهاى خودمراقبتى \\ بيماران مبتلا به ديابت نوع دو}

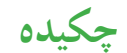

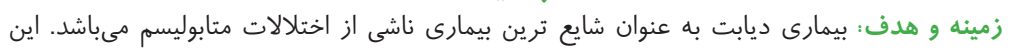

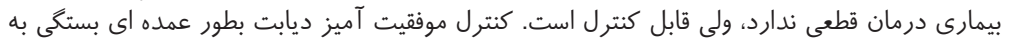

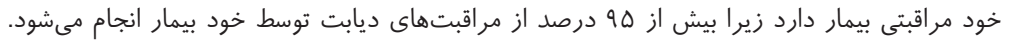

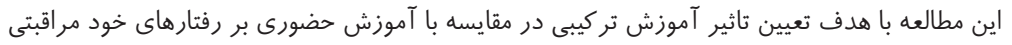

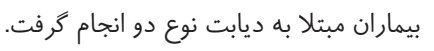

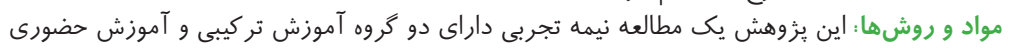

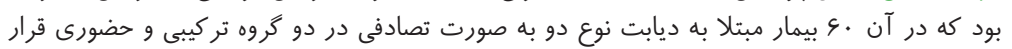

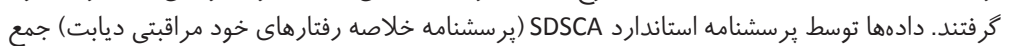

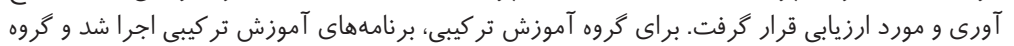

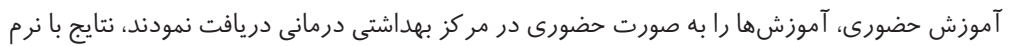

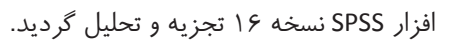

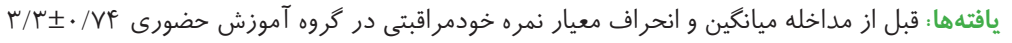

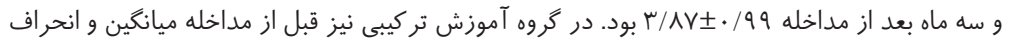

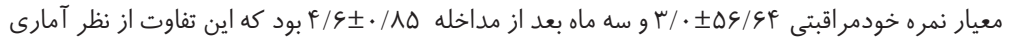

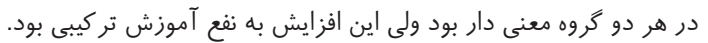

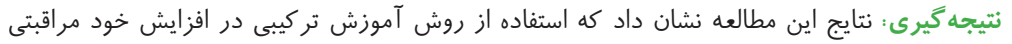

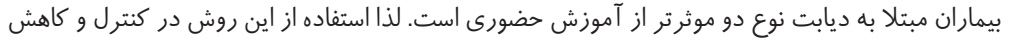

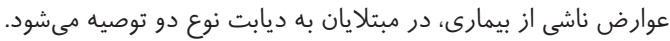

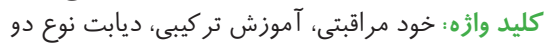

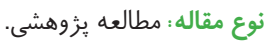

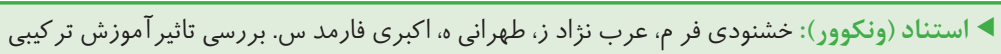

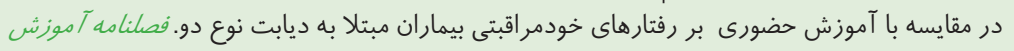

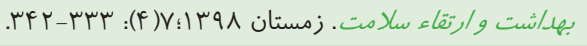

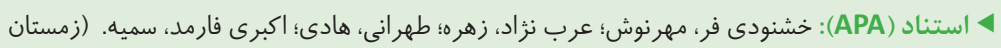

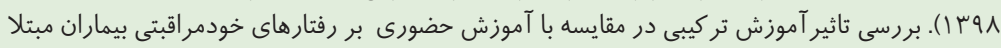

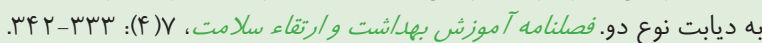

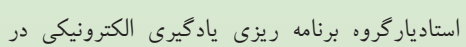

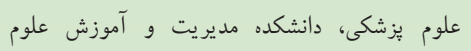

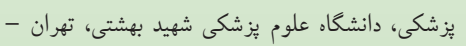
ايران. زهره عرب نزواد

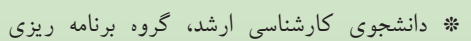

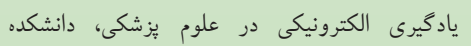

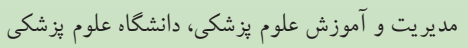
شهيد بهشتى، تهران، ايران. (نويسنده مسئول): بـت الكترونيك:

ArabnejadZ1@mums.ac.ir

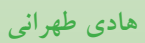
استاديار كروه آموزش بهداشت و ارتقاء سلامت، مركز تحقيقات عوامل اجتماعى موثر بر سلامت، دانشكاه علوم يُشكى مشهد، مشهد - ايران.

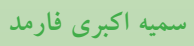

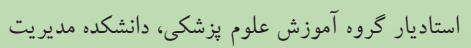
و آموزش علوم يزشكى ، دانشكاه علوم بز شكى شئى شهيد بهشتى، تهران - ايران.

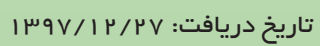
تاريخ يذيرش: 
خود مر اقبتى، توسط آموزش فعال امكان يذير بوده و آموزش

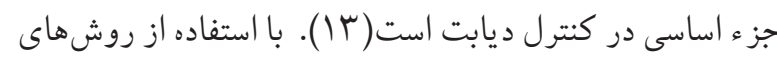

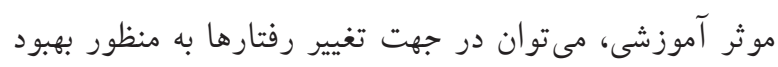

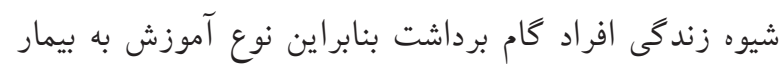

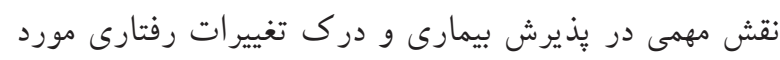

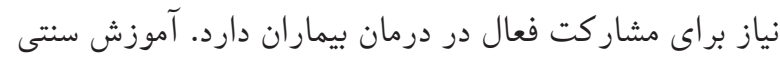

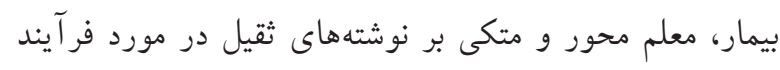

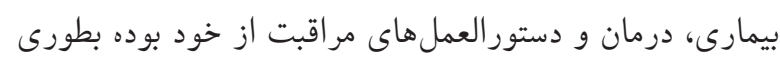

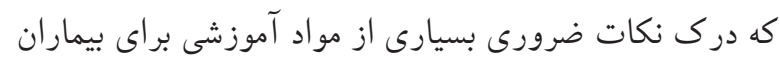
مشكل بوده است، تحقيقات مختلف نشان داده كه آموزشهاى ندراي

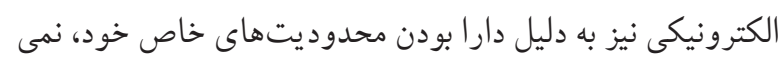

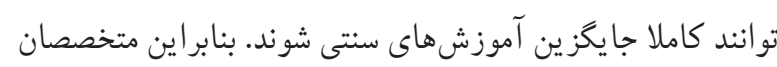

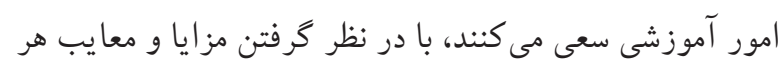

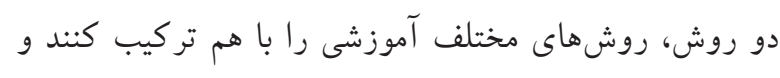

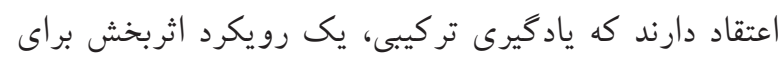

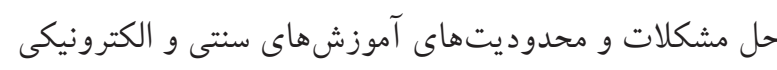

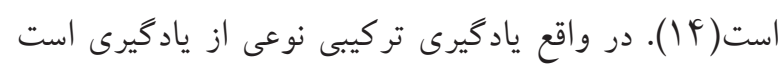

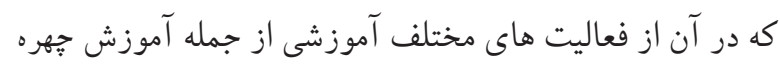

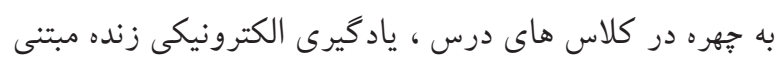

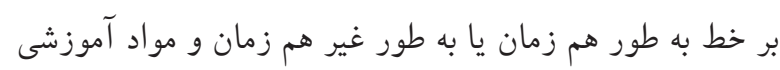

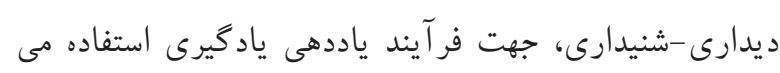

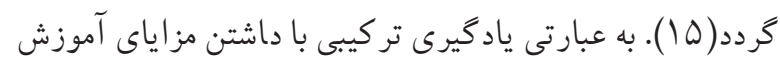

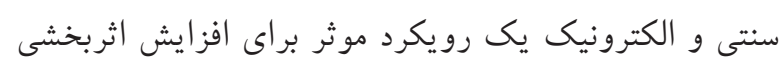

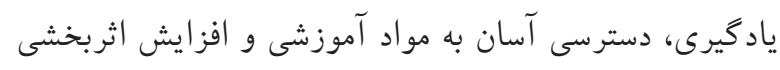

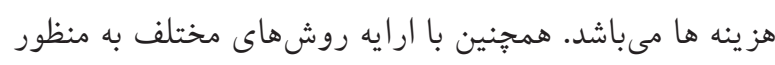

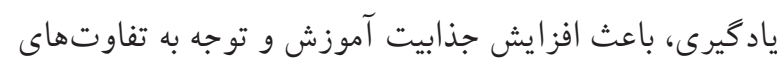

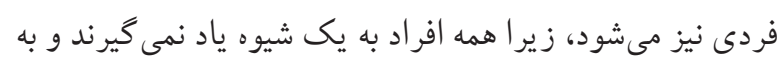

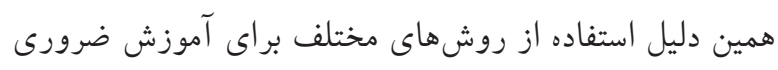

$$
\text { به نظر مىرسد(19). }
$$

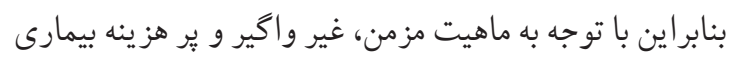

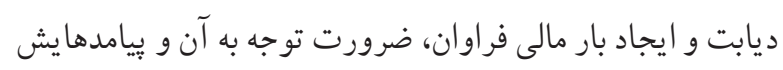

مقامها بيمارى ديابت به عنوان شايع ترين بيمارى ناشى از اختلالات متابوليسم

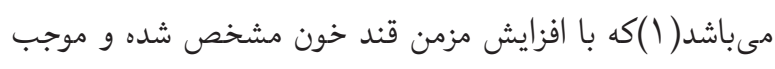

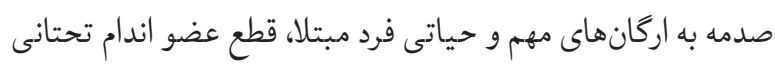

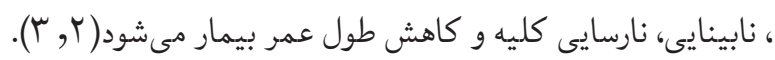

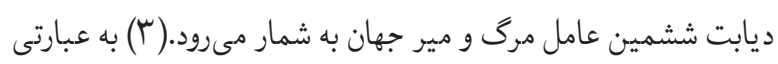

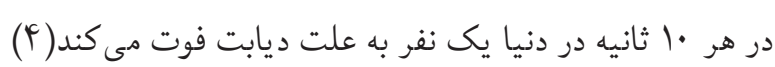

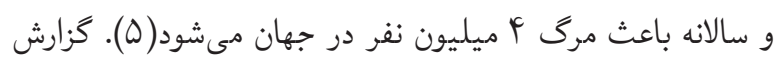

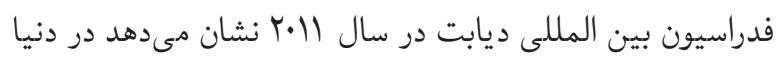

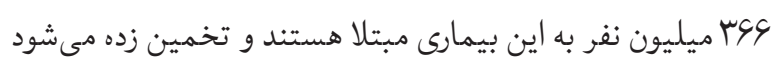

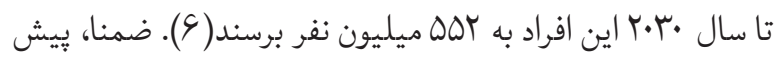

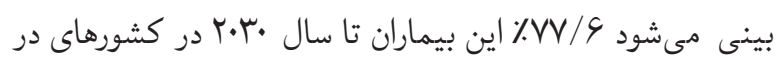

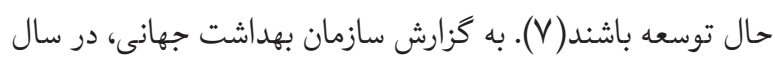

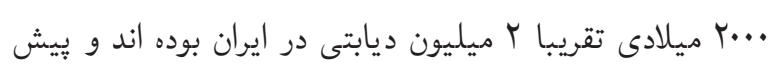

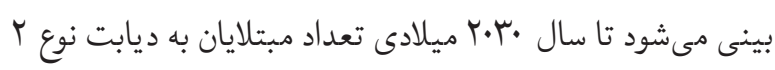
به ب/9 ميليون نفر افزايش بيدا كند(م). ديابت بيمارى مزمنى است كه درمان قطعى ندارد ، ولى في بلى

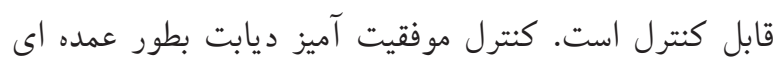

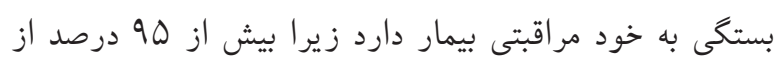

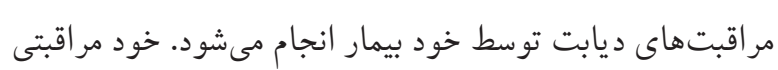

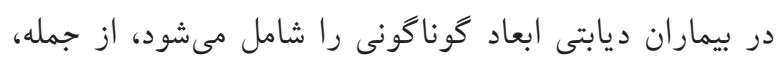

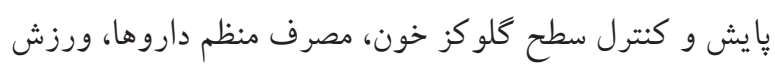

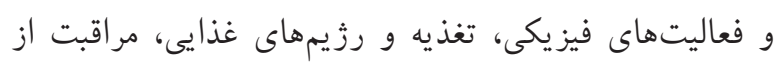

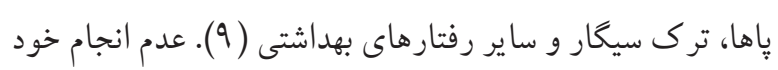

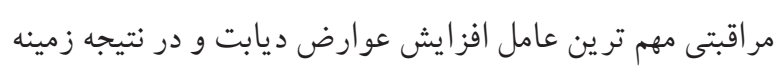

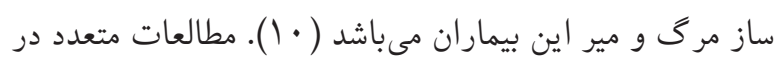

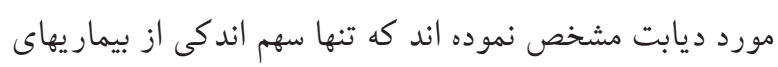

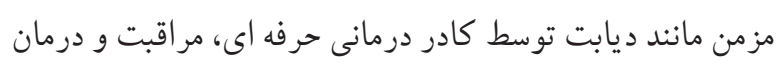

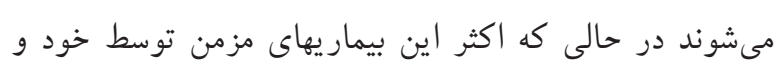

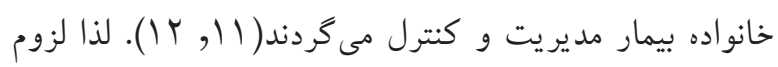

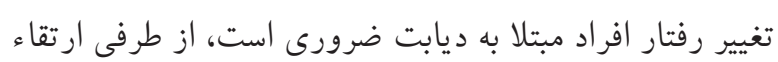


تمايل به شركت در مطالعه، داشتن مشكلات شناختى، رفتارى و ديابت باردارى بود. در اين ثُروهش بر اساس معيارهاى ورود

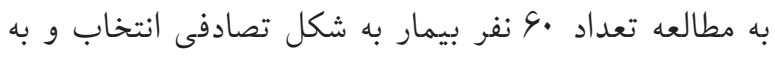

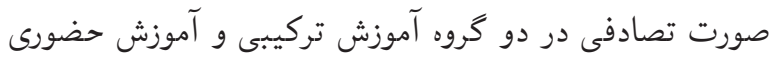
وارد شدند. حجم نمونه بر اساس معيارهاى ورود به مطالعه و

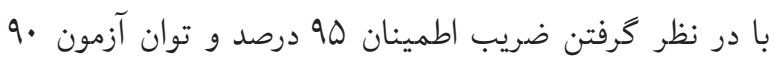
درصد، با استفاده از فرمول مقايسه ميانگين زير و نتايج يزوهش

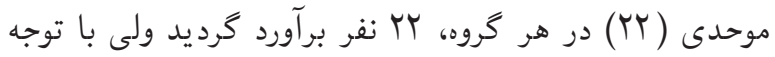

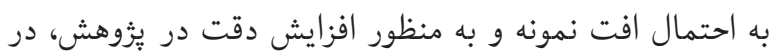

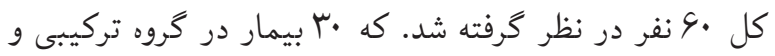
•r بيمار در كروه حضورى قرار كرفتند.

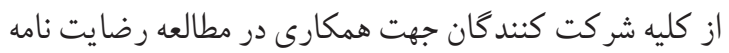
مكتوب دريافت شد. جهت جمع آورى اطلاعات فردى و بيمارى از يرسشنامه اى مشتمل بر ^ مسئو ال در رابطه با (سن، جنس، وضعيت

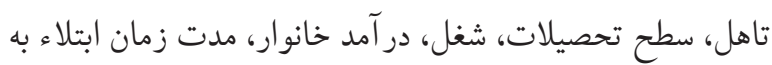
بيمارى، وضعيت درمان) استفاده شد. جهت سنجش وضعيت خود مراقبتى بيماران از برسشنامه خلاصه رفتارهاى خودمر اقبتى ديابت

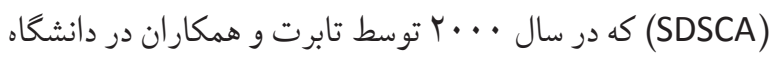

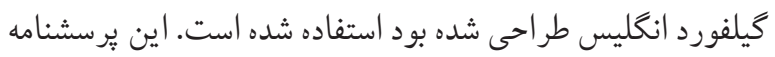
شامل r| إعنوان است كه هر عنوان، بر اساس مقياس ليكرت

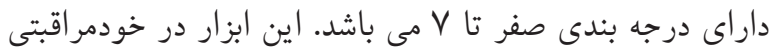

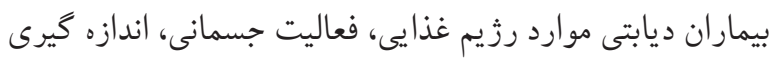

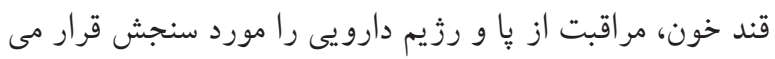
دهد. در اين پِرسشنامه جنانجه بيمار رفتار خودمراقبتى مورد نظر

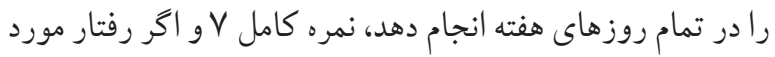
نظر را انجام ندهد، نمره صفر در نظر گرفته مى شود. حداقل نمره

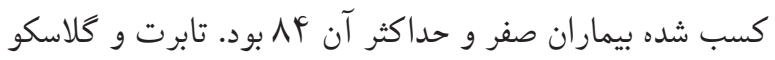
در مطالعات متعددى روايى و وايايى ثرسشنامه حاضر را به اثبات رسانيده اند. اين يرسشنامه در مطالعات متعددى در دنيا بكار گرفته

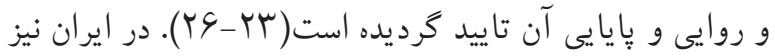

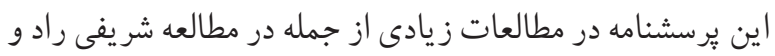

لازم به نظر مىرسد(V) ال. از آنجا كه درمان بيمارىهاى مزمن به ميزان زيادى بستكى به رفتار خود مر اقبتى خود بيمار دارد( (1) و

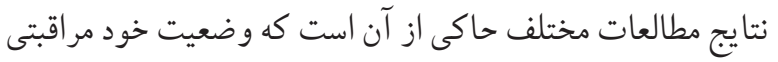
در بيماران ديابتى در حد مناسبى قرار ندارد به صورتى كه اعمال

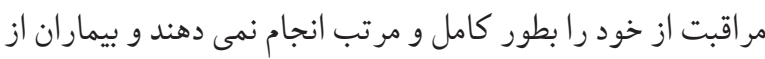

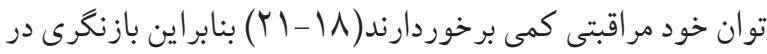

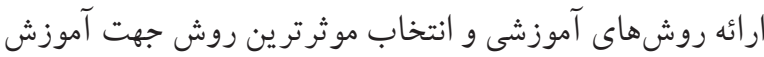

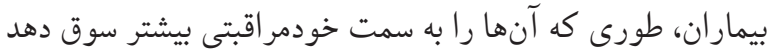

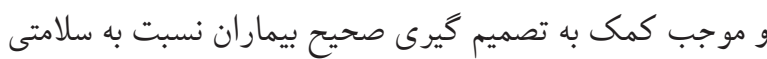

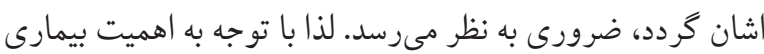

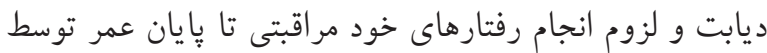

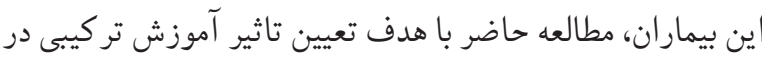
مقايسه با آموزش حضورى بر رفتارهاى خودمر اقبتى بيماران مبتلا

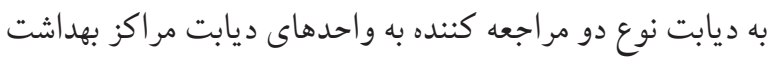
شهر مشهد طر احى گرديده است.

مو اد و روشها اين مطالعه از نوع نيمه تجربى با دو گرووه آموزش تركيبى و آموزش حضورى بود كه در سال 9V در شهر مشهد انجام شد. براى انجام اين مطالعه، از بين كليه واحدهاى ديابت مراكز بهداشت شهر مشهد، يك مركز (مركز ديابت شهيد قدسى)، به إنه

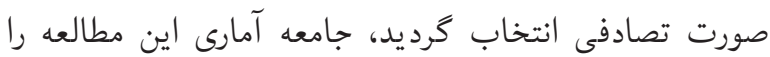
تمام بيماران مبتلا به ديابت نوع Y كه در مركز ديابت شهيد قدسى مشهد داراى يرونده بودند، تشكيل مى داد. معيارهاى ورود به مطالعه شامل: تاييد بيمارى ديابت نوع دو توسط يزشك، ترى

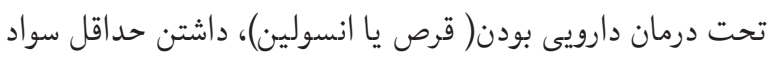
خواندن و نوشتن ، داشتن سن بالاى \ل سال، داشتن تلفن همراه و توانايى استفاده از آن، دسترسى به اينترنت، توانايى استفاده بـ باهي از كامييوتر، داشتن شبكه يُيام رسان مجازى و توانايى استفاد از آن، تمايل براى شركت در مطالعه و معيارهاى خروج شامل:

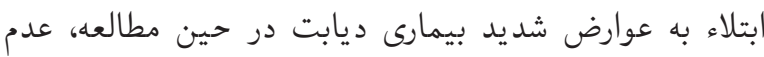


كرديد. همجنين به منظور بررسى اختلاف ميانگين بين دو گروه آزمايشى در طى مراحل مطالعه با توجه به نرمال بودن متغيرها

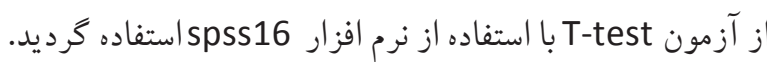

يافتهاه

در اين مطالعه، نمونه مورد بررسى •ونفر مى باشد كه •" نفر در

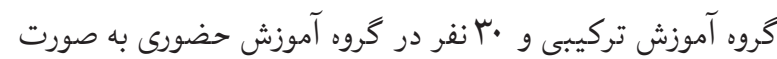

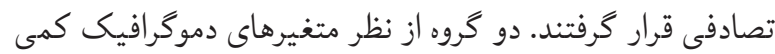

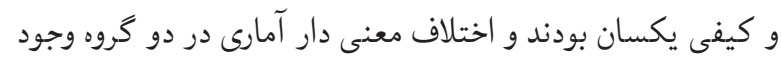

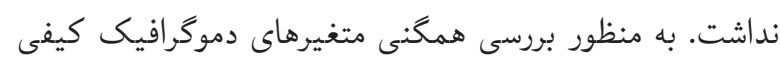

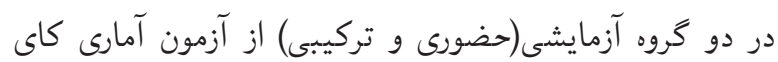

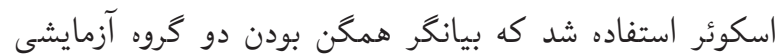
مى باشد از نظر همخنى متغيرهاى دموكرافيك كمى از آزمون T-test دموكرافيك كمى همخن مى باشند و اختلافى بين دو گروه وجود

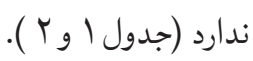

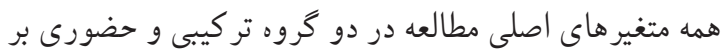
اساس آزمون كلمو گروف اسميرنوف داراى توزيع نرمال بودند. با دمال توجه به اين امر از آزمونهاى هار امتريك براى مقايسه ميانكينها

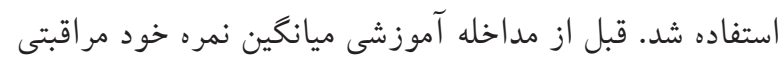
در گروه حضورى بود دو گروه از نظر ميانگين نمره خودمر اقبتى يكسان بودند و ورى

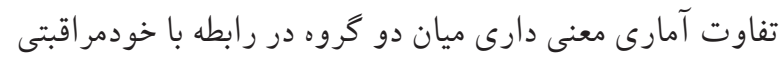

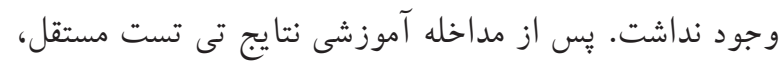

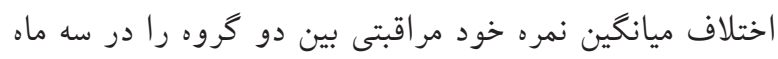

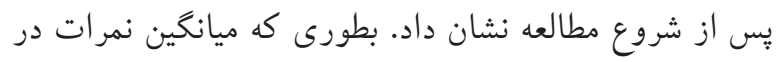

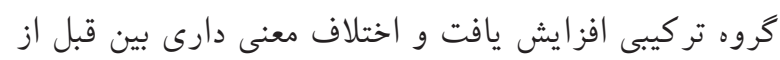

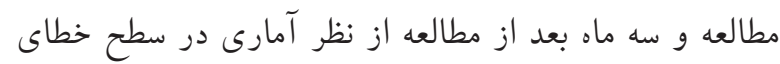

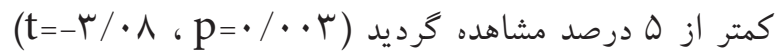

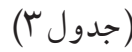

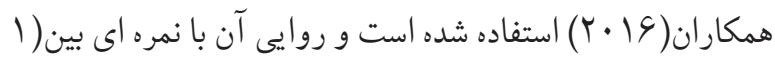

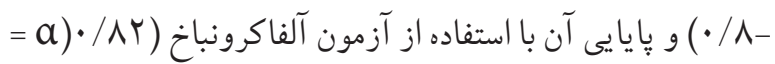
مورد تاييد قرار كرفته است.

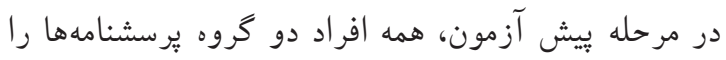

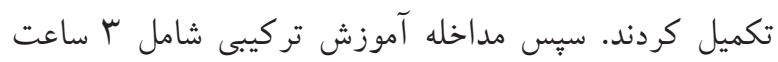
آموزش حضورى در مورد كليات ديابت، تعريف ديابت، علت

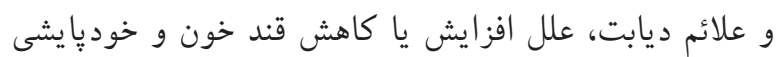
قند خون به صورت ب جلسه • 9 دقيقه اي در ابتدا و انتهاى دوره

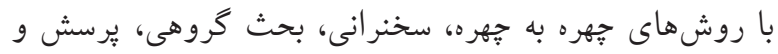

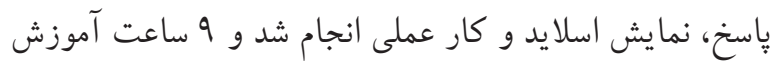

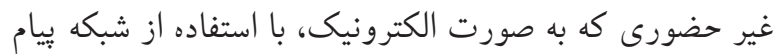
رسان مجازى تلكرام شامل: متن، فيلم، يوستر، بحث و كفتكو،

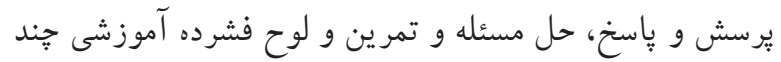

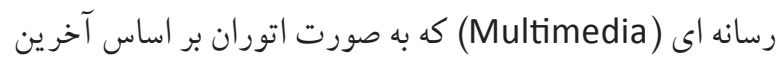
سرفصلهاى وزارت بهداشت، درمان و آموزش بز شكى تهيه شده

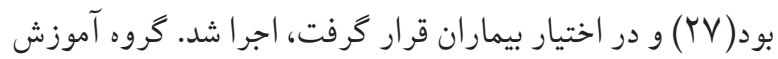

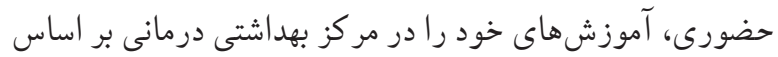

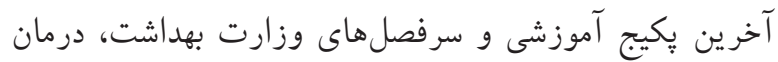

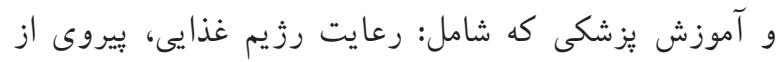

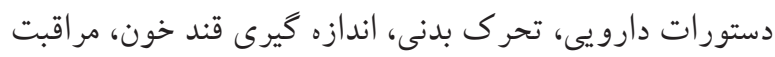

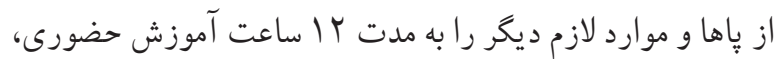
به صورت ^ جلسه • 9 دقيقه اي در روزهاى يكشنبه و ينج شنبه هر هفته به مدت يك ماه دريافت نمودند. يس از انجام مداخله

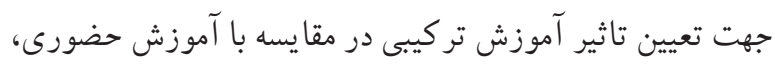

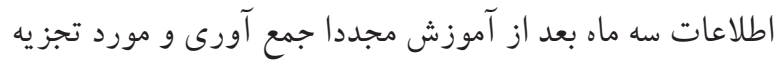
و تحليل قرار گرفت. جهت تجزيه و تحليل دادههاى بدست آمده

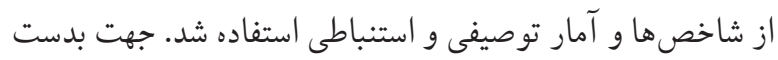

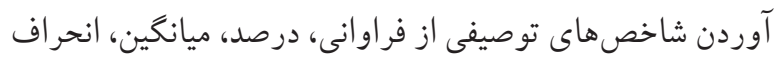

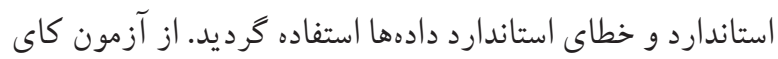
دو براى مقايسه متغيرهاى جمعيت شناختى كيفى و از آزمون تى تست براى مقايسه متغيرهاى جمعيت شناختى كمى استفاده 
جدول ا. مقايسه متغير هاى جمعيت شناختى كيفى در دو گَروه آموزشى

\begin{tabular}{|c|c|c|c|c|c|c|c|c|}
\hline \multirow{2}{*}{ آزمون آمارى } & \multicolumn{2}{|c|}{ كل } & \multicolumn{2}{|c|}{ كروه تر كيبى } & \multicolumn{2}{|c|}{ گروه حضورى } & \multirow{2}{*}{\multicolumn{2}{|c|}{ متغير }} \\
\hline & درصد & 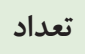 & درصد & 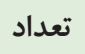 & درصد & تعداد & & \\
\hline \multirow{3}{*}{$\begin{array}{l}r<\cdot / \cdots 1 \\
\mathrm{P}^{r}=\cdot / s q\end{array}$} & $r$. & rF & r. & Ir & $r$. & Ir & 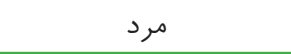 & \multirow{3}{*}{ جنسيت } \\
\hline & c. & קs & s. & 11 & s. & 11 & زن & \\
\hline & $1 \cdots$ & s. & $1 \cdots$ & r. & $1 \cdots$ & r. & كل & \\
\hline \multirow{4}{*}{$\begin{array}{l}r=\cdot / 11 f \\
P=\cdot / 9 r\end{array}$} & $r I / V$ & 10 & r & $\checkmark$ & $r s / V$ & $\wedge$ & زيردييلم & \multirow{4}{*}{ ميزان تحصيلات } \\
\hline & $\mathrm{rr} / \mathrm{r}$ & rF & f. & ir & f. & ir & دييلم & \\
\hline & mo & rl & $\mu c / V$ & 11 & س س & 1. & بالاتر از دييلم & \\
\hline & $1 \cdots$ & s. & $1 \cdots$ & r. & $1 \cdots$ & r. & كل & \\
\hline \multirow{4}{*}{$\begin{array}{l}r=1 / \wedge r \\
\mathrm{P}=\cdot / \uparrow V\end{array}$} & $\mu F / \Delta$ & $r$. & $F \mid / F$ & Ir & $r V / S$ & $\wedge$ & كارمند و بازنشسته & \multirow{4}{*}{ 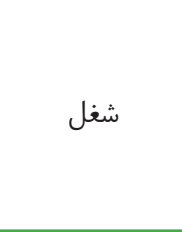 } \\
\hline & $10 / 0$ & 9 & $1 \cdot / \mu$ & r & $r \cdot / V$ & 4 & كارگر و شغل ازاد & \\
\hline & $\Delta$. & rq & $\boldsymbol{\varphi} \wedge / \mu$ & if & $01 / V$ & 10 & خانه دار & \\
\hline & $1 \cdots$ & $\Delta \wedge$ & $1 \cdots$ & rq & $1 \cdots$ & rq & 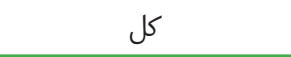 & \\
\hline \multirow{5}{*}{$\begin{array}{l}r=r / \Delta I \\
P=\cdot / \Delta r\end{array}$} & $\mu \mathrm{ll}$ & 19 & $r G / V$ & $\wedge$ & rG/V & 11 & كمتر از · ..ه هزار تومان & \multirow{5}{*}{ درآمد } \\
\hline & $1 \wedge / \mu$ & 11 & 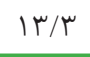 & f & 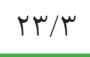 & $\checkmark$ & بين ·ه تا يك ميليون & \\
\hline & $\mu \varsigma / V$ & $r r$ & $\mu r / r$ & r & r. & 9 & بين يك تا دو ميليون & \\
\hline & 1 & $\wedge$ & $19 / V$ & $\Delta$ & 1. & $\mu$ & بيشتر از دو ميليون & \\
\hline & $1 \cdots$ & 4 . & $1 \cdots$ & r. & $1 \cdots$ & r. & كل & \\
\hline \multirow{3}{*}{$\begin{array}{c}r<\cdot / \cdots 1 \\
\mathrm{P}=1\end{array}$} & 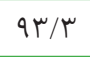 & $\Delta S$ & 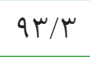 & rᄉ & 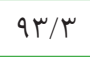 & rᄉ & متاهل & \multirow{3}{*}{ 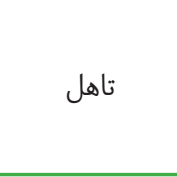 } \\
\hline & $s / V$ & f & $s / V$ & r & $s / V$ & r & 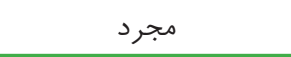 & \\
\hline & $1 \cdots$ & 4 . & $1 \cdots$ & r. & $1 \cdots$ & r. & 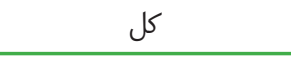 & \\
\hline \multirow{4}{*}{$\begin{array}{l}r=1 / 10 \\
\cdot / 9 V=P\end{array}$} & $V \mu / r$ & fF & $V S / V$ & r & $\checkmark \cdot$ & rl & داروى خوراكى & \multirow{4}{*}{ نوع درمان } \\
\hline & $\Lambda / \mu$ & $\Delta$ & 1 . & r & $s / V$ & r & انسولين درمانى & \\
\hline & $\mid \wedge / \mu$ & 11 & س & r & س & V & هر دو & \\
\hline & $1 \cdots$ & 4 . & $1 \cdots$ & r. & $1 \cdots$ & r. & كل & \\
\hline
\end{tabular}

جدول r. مقايسه ميانغَين و انحراف معيار متغيرهاى دموكَرافيك كمى در دو كَروه آموزشى

\begin{tabular}{|c|c|c|c|c|c|c|}
\hline \multirow{2}{*}{ مقدار احتمال } & \multirow{2}{*}{ آماره آزمون } & \multicolumn{2}{|c|}{ كروه تركيبى } & \multicolumn{2}{|c|}{ كروه حضورى } & \multirow{2}{*}{ متغير } \\
\hline & & انحراف معيار & ميانگين & انحراف معيار & ميانغين & \\
\hline . & $\cdot / 9 \cdot V$ & $11 / \cdot F$ & $\Delta 9 / \mu$ & $q / \cdot V$ & sI/V & سن \\
\hline$\cdot /$ MAN & $\cdot / \wedge \mathrm{V}$ & $\Delta / F \wedge$ & $9 / 94$ & s/119 & $11 / r_{s}$ & مدت ابتلا به بيمارى \\
\hline
\end{tabular}


جدولَّ: مقايسه ميانغين و انحراف معيار ميانگين نمره خودمر اقبتى در دو گروه تركيبى وحضورى

\begin{tabular}{|c|c|c|c|c|c|c|}
\hline \multirow{2}{*}{ مقدار احتمال } & \multirow{2}{*}{ آماره آزمون } & \multicolumn{2}{|c|}{ كروه تركيبى } & \multicolumn{2}{|c|}{ كروه حضورى } & \multirow{2}{*}{ متغير } \\
\hline & & انحراف معيار & ميانگين & انحراف معيار & ميانگين & \\
\hline.$/ I F \wedge$ & $-1 / 48$ & $\cdot / g p$ & T/DG & $\cdot / V^{F}$ & 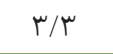 & شروع مطالعه \\
\hline *. $/ . r$ & $-\mu / \cdot \Lambda$ & $\cdot / 1 \Delta$ & $F / 4$ & .199 & r/AV & سه ماه يس از مداخله \\
\hline & & \multicolumn{2}{|c|}{ (r/l } & \multicolumn{2}{|c|}{$0 / 11$} & آماره آزمون \\
\hline & & \multicolumn{2}{|c|}{ 米< $/ \ldots 1$} & \multicolumn{2}{|c|}{ 䊉./.rI } & مقدار احتمال \\
\hline
\end{tabular}

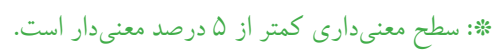

بحث نتيجه كيرى

استفاده كرده بودند نشان دادند بيمارانى كه آموزش اينترنتى دريافت

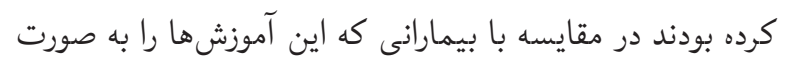

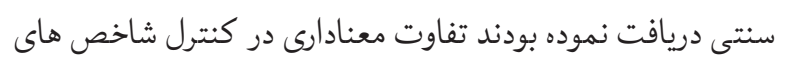

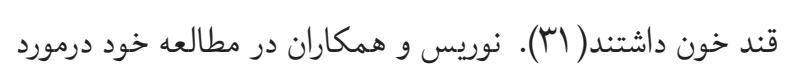

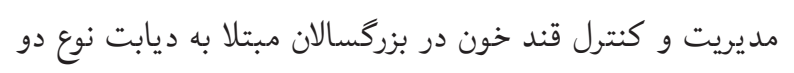

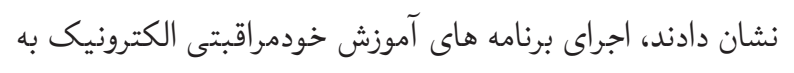

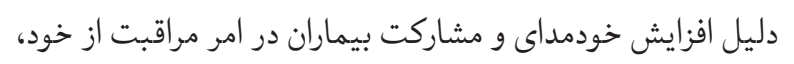
يك روش مناسب براى آموزش اين بيماران مىباشد( (Tس). در مطالعه

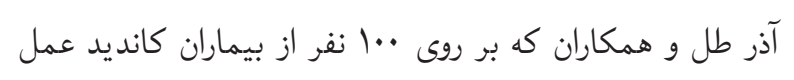
جراحى بسترى در بخش ارتويدى يكى از بيمارستانهاى دانشخاه

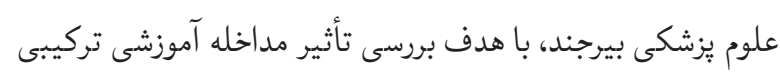

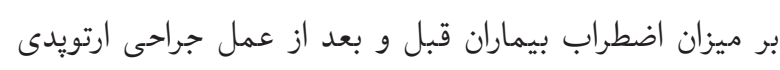

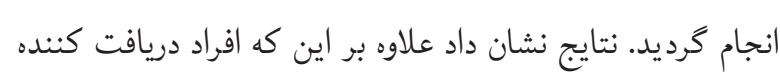

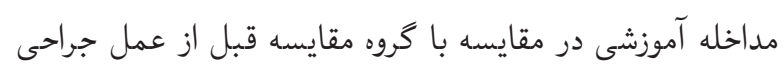

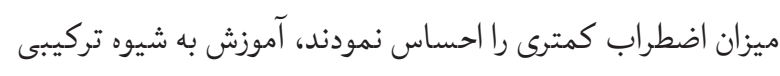

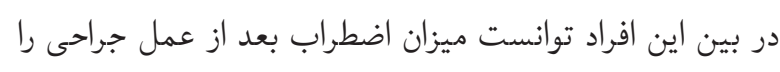

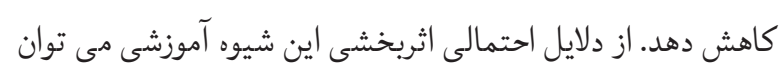
به تلفيق مناسب رسانه هاى آموزشى مختلف به منظور حمايت مؤثر

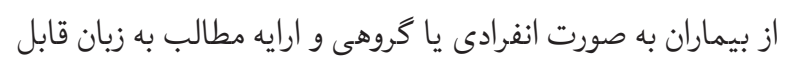

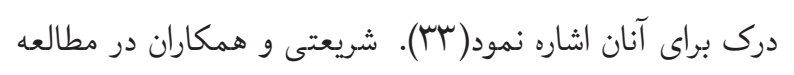

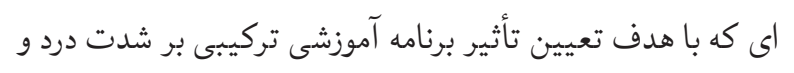

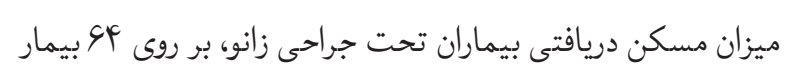

نتايج اين يزوهش افزايش معنى دارى را در ميانگين نمره خودمراقبتى ليقى

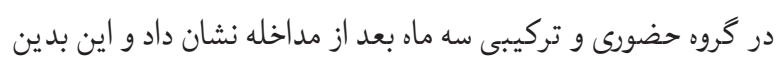
معنى است كه هر دو روش آموزشى موثر بوده است اما ميانگين

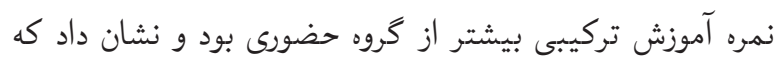

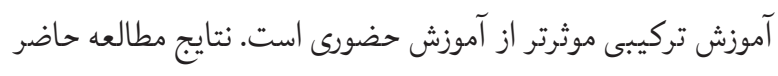

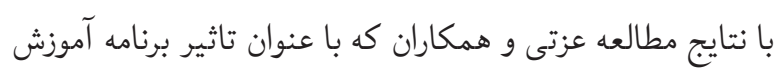
تركيبى بر رفتار غربالكرى سرطان سرويكس در زنان خانه دار انجام شد همسو مىباشد. در آن مطالعه يس از مداخله آموزشى ميانكين

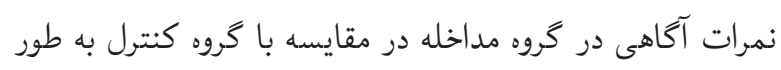

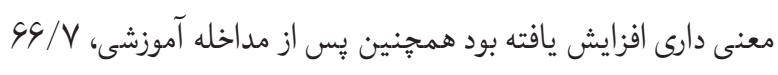

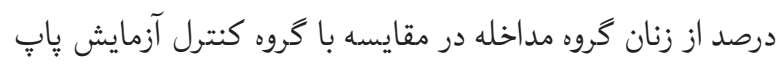

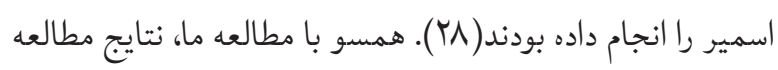

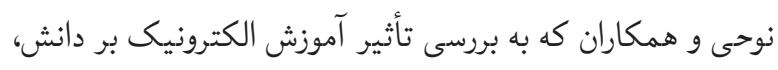

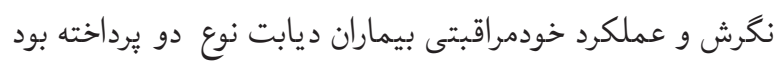

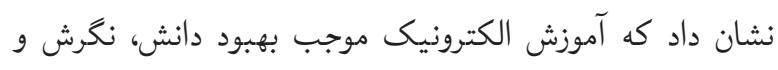
عملكرد خودمراقبتى در بيماران گروه مورد بعد از آموزش شده است.

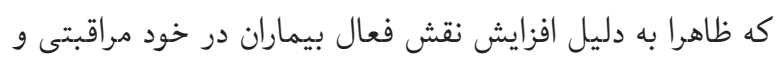

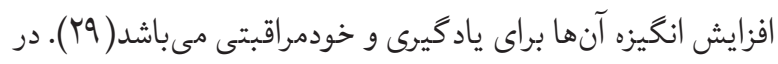
مطالعه ولش جى و همكاران در مورد مديريت ديابت و كنترل قند

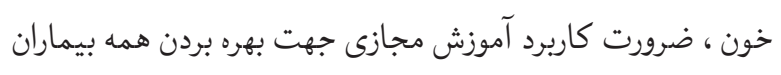

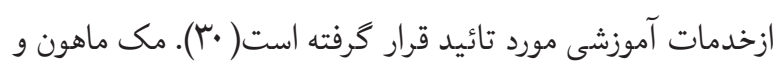
همكاران درمطالعه خود كه جهت آموزش بيماران ديابتى از اينترنت 
افراد نباشد لذا يبشنهاد مىشود در يزوهشهاى آينده علاوه بر اندازه

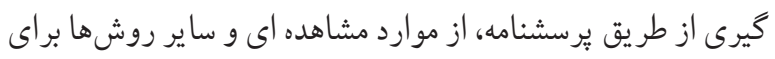
افزايش دقت اطلاعات استفاده شود و يُزو هشهاى تكميلى براى بردي

$$
\begin{aligned}
& \text { ساير بيمارىهاى مزمن انجام يذيرد. } \\
& \text { نتيجه كيرى }
\end{aligned}
$$

بر اساس يافتههاى مطالعه حاضر نمرات حاصل از آزمون مقادير

اندازه گيرى نشان داد، آموزش تركيبى بر خود مر اقبتى بيماران مبتلا

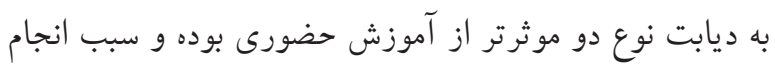

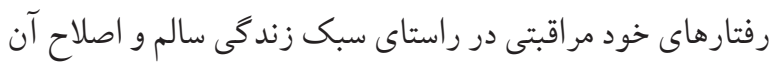

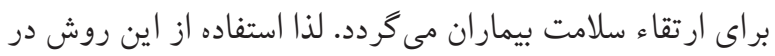

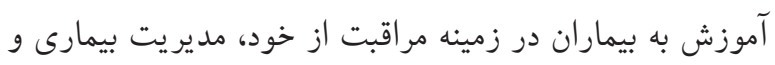

$$
\text { كنترل عوارض آن بيشنهاد مىشود. }
$$

اين مقاله بخشى از پايان نامه كارشناسى ارشد با شناسه اخلاق

IR.SBMU.SME.REC.1397.011 مىباشد كه بدين وسيله بانس يُزوهشگران مراتب تشكر و قدردانى خود را از معاونت يُوهشى

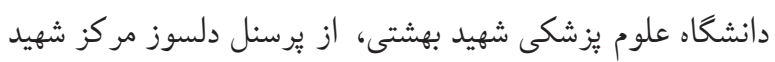
قدسى و از بيماران محترم شركت كننده در مطالعه اعلام مى دارند.

$$
\text { تعارض در منافع }
$$

سهم تمامى نويسند گان در اين مطالعه يكسان است و هيجگُ نه

$$
\text { تضاد منافعى وجود ندارد. }
$$

\section{References}

1. Noroozi M, Madmoli Y, Derikvand M, Saki M, Moradi kalboland M. Investigating Health Literacy Level and Its Relation with Some Factors in Patients with Type 2 Diabetes in Ahvaz -2018. Journal of Health Literacy. 2019;4(1):43-52. doi.org/10.22038/jhl.2019.39813.1049

2. Heidari S, Nouri Tajer M, Hosseini F, Inanlou M, Golgiri F, Shirazi F. Geriatric family support and diabetic type-2 glycemic control. Iranian Journal of Ageing. 2008;3(2):57380.

3.Schoenberg NE, TraywickLS,Jacobs-LawsonJ, KartCS. Diabetes self-care among a multiethnic sample of older adults. Journal of cross-cultural gerontology. 2008;23(4):361-76. https://doi.org/10.1007/s10823-008-9060-z
كانديد جراحى تعويض مفصل زانو كه به صورت بلوى تصادفى جهارتايى در دو گروه آزمون و كنترل قرار گرفته بودند انجام داد.

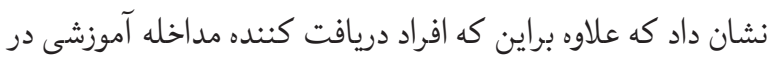

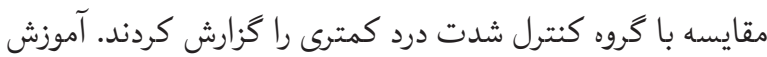

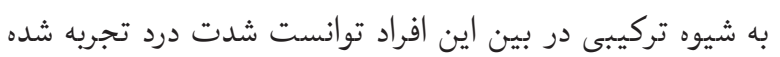

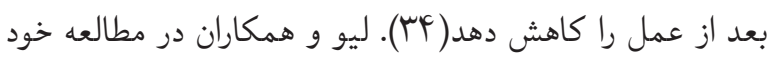

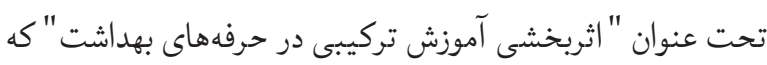

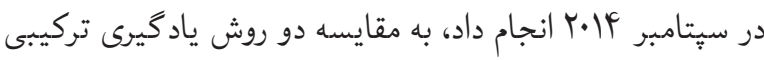
و ياد گيرى غيرمتمركز (آموزش الكترونيكى خالص و آموزش جهره به جهره خالص) در دانشجويان حرفههاى بهداشت برداخت و نشان داد آموزش تركيبى اثر مثبت مناسبى بر روى ياد خيرى دانشجويان

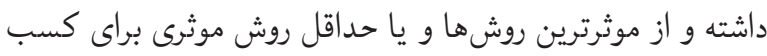

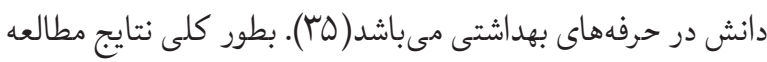

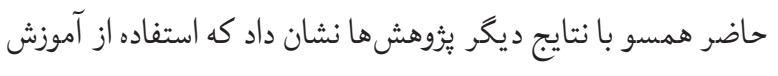
تركيبى جذابيت بيشترى براى بيماران دارد و با افزايش انكيزه

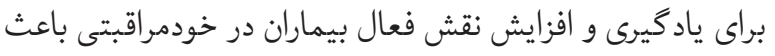

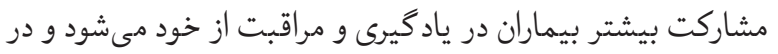

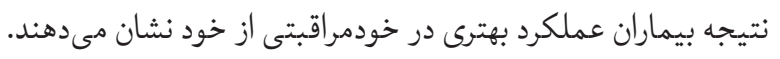

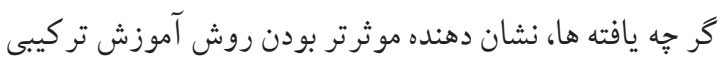

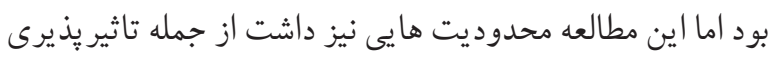

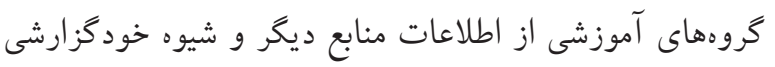

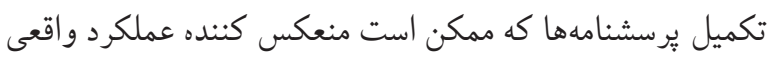

PMid:18369715 PMCid:PMC3079270

4. Hamadzadeh S, Ezatti Z, Abedsaeidi Z, Nasiri N. Coping styles and self-care behaviors among diabetic patients. Iran Journal of Nursing. 2013;25(80):24-33.

5. Abdoli S, Ashktorab T, Ahmadi F, Parvizi S. Barriers to and Facilitators of Empowerment in People with Diabetes. Iranian Journal of Endocrinology and Metabolism. 2009;10(5):455-64.

6. Alidosti $M$, tavassoli e. Investigating Health literacy, knowledge and self-efficacy in patients with type 2 diabetes referring to health centers in shahrekord. Journal of Health Literacy. 2019;3(4):36-45.doi.org/10.22038/ jhl.2019.38005.1031 
7. Hemmati Maslak pak M, Parizad N, Khalkhali H. The effect of Tele-Education by telephone and short message service on glycaemic control in patient with type 2 diabetes. The Journal of Urmia Nursing and Midwifery Faculty. 2012;10(4):580-8.

8. Darvishpoor Kakhki A, Abed Saeedi Z, Yaghmaie F, Alavi Majd $\mathrm{H}$, Montazeri A. Survey correlation between quality of life and disease and demographic variables of diabetic patients referred to Tehran hospitals in 2004. Iranian Journal of Endocrinology and Metabolism. 2006;8(1):4956.

9. Anderson $R$, Funnell $M$, Carlson A, Saleh-Statin N, Cradock S, Skinner TC. Facilitating self-care through empowerment. Psychology in diabetes care. 2000:69-97. https://doi.org/10.1002/0470846569.ch4

10. Khazarlo S, Feizi A. The relationship between self-efficacy and function in patients suffering diabetes, diabetes clinic Oromie. School of Nursing and Midwifery. 2013;10(3):36975.

11. Agha Molaei T, Mohammad K, H. E. Application of health belief model to behavior change of diabetic patients. payesh. 2005;4(4):263-9.

12. Brunner LS, Smeltzer S, Suddarth D. Brunner and suddarth's textbook of medical-surgical nursing; Vol. 1. Language. 2010;27:1114-2240p.

13. Wahba H, Chang Y-F. Factors associated with glycemic control in patients with type 2 diabetes mellitus in rural areas of the United States. Insulin. 2007;2(3):134-41. https://doi.org/10.1016/S1557-0843(07)80042-X

14. Peyman N, Rezai-Rad M, Tehrani $H$, Gholian-Aval M, Vahedian-Shahroodi M, Miri HH. Digital Mediabased Health Intervention on the promotion of Women's physical activity: a quasi-experimental study. BMC public health. 2018;18(1):134.. https://doi.org/10.1186/s12889-018-5025-5 PMid:29334970 PMCid:PMC5769504

15. Abdollahi D. The Role of Educational Planner in E-Learning Process Improvement: Developing Teaching Strategies, Teachers' Rolls, Concept, and Evaluation System. Iranian Journal of Health Education and Health Promotion. 2017;4(4):329-38. https://doi.org/10.18869/acadpub.ihepsaj.4.4.329

16. Sevari K, Falahi M. Develop and improve teaching and learning through blended learning. Journal of Educational Studies (NAMA). 2017;5(10):20-6.

17. Morowatisharifabad M, Rouhani Tonekaboni N. Perceived self-efficacy in self-care behaviors among diabetic patients referring to Yazd Diabetes Research Center. Journal of Birjand University of Medical Sciences. 2008;15(4):91-9.

18. Zabihi A, Jafarian Amiri R, Babaieasl F, Eshkevari N, A. B. Self Care Behaviors in Diabetic Patients Referring to Diabetes Clinics in Babol. Journal Of Babol University Of
Medical Sciences. 2010;12(4):72-8.

19. Mahmood K1, AH. A. Glycemic control status in patients with type-2 diabetes. J Coll Physicians Surg Pak 2005;15(6):323-5.

20. Shakibazadeh E, Rashidian A, Larijani B, Shojaeezadeh D, Forouzanfar M, Karimi Shahanjarini A. Perceived Barriers and Self-efficacy: Impact on Self-care Behaviors in Adults with Type 2 Diabetes. Hayat. 2010;15(4):69-78.

21. Baghaei P, Zandi M, Vares Z, Masoudi Alavi N, AdibHajbaghery M. Self care situation in diabetic patients referring to Kashan Diabetes Center, in 2005. Feyz Journal of Kashan University of Medical Sciences. 2008;12(1):8893.

22. Monireh Movahedi MSE, Nadiya Gholamipour The Effect of Blended learning-Based Social Networks on Second Year High School Students' Self-efficacy in Math. Teaching and learning technology. 2015(3):7-22.

23. Toobert DJ, Hampson SE, Glasgow RE. The summary of diabetes self-care activities measure: results from 7 studies and a revised scale. Diabetes care. 2000;23(7):943-50. https://doi.org/10.2337/diacare.23.7.943 PMid:10895844

24. Kim S, Love F, Quistberg DA, Shea JA. Association of health literacy with self-management behavior in patients with diabetes. Diabetes care. 2004;27(12):2980-2. https://doi.org/10.2337/diacare.27.12.2980 PMid:15562219

25. Lin EH, Katon W, Von Korff M, Rutter C, Simon GE, Oliver $M$, et al. Relationship of depression and diabetes self-care, medication adherence, and preventive care. Diabetes care. 2004;27(9):2154-60. https://doi.org/10.2337/diacare.27.9.2154 PMid:15333477

26. Skarbek EA. Psychosocial predictors of self-care behaviors in type 2 diabetes mellitus patients: Analysis of social support, self-efficacy, and depression. 2005.

27. Noorabadi Gh, Mahdavi A, et al. Prevention, control and treatment of diabetes. Second editor. Hamedan: Oxay publication. 2014. [Persian]

28. Ezzati E, Shariat F, Moradi F, babazadeh T. The Effect of a Blended Educational Program (BEP) on Cervical Cancer Screening Behavior among Housekeeper Women in West Eslamabad in 2016:an Application of Health Belief Model. journal of ilam university of medical sciences. 2017;25(1):110-20. https://doi.org/10.29252/sjimu.25.1.110

29. Noohi E. Khandan M, Mirzazadeh A. Effective of electronic education on knowledge attitude and self-care in patient's diabetic type 2 refer to diabetic center of Kerman University of medical science. Iranian journal of nursing research. 2011;6:73-80.

30. Welch G, Garb J, Zagarins S, Lendel I, RA. G. 
Nurse diabetes case management interventions and blood glucose control: Results of a metaanalysis. Diabetes Res Clin Pract. 2010;88(1):1-6. https://doi.org/10.1016/j.diabres.2009.12.026 PMid:20116879

31. McMahon GT, Gomes HE, Hickson Hohne S, all. e. Web-based care management in patients with poorly controlled diabetes. Diabetes Care. 2005;28(7):1624-9. https://doi.org/10.2337/diacare.28.7.1624 PMid:15983311 PMCid:PMC1262644

32. Norris SL, Lau J, Smith SJ, Schmid CH, MM. E. Selfmanagement education for adults with type 2 diabetes: a meta-analysis of the effect on glycemic control. Diabetes Care. 2002;25(7):1159-71. https://doi.org/10.2337/diacare.25.7.1159 PMid:12087014
33. Tol A, Pardel Shahri M, Esmaelee Shahmirzadi S, Mohebbi B, Javadinia S. Effect of blended education program on anxiety among orthopedic patients' surgery. Journal of Nursing Education. 2013;2(3):1-8.

34. Shariati A, Amirmohseni L, Baraz S, Latifi SM. Effectiveness of Blended Instruction on Pain and Requirement for Analgesic after Knee Arthroplasty Surgery. Journal of Clinical Nursing and Midwifery. 2016;5(3):1-11.

35. Liu Q, Peng W, Zhang F, Hu R, Li Y, Yan W. The effectiveness of blended learning in health professions: Systematic review and Meta-Analysis. J Med Internet Res. 2016;18(1):e2. h tt p s : / / d o i . org / $10.2196 /$ j m i r. 4807 PMid:26729058 PMCid:PMC4717286 